\title{
A VOZ DE UM EDITOR POPULAR
}

\author{
Jerusa Pires Ferreira*
}

\begin{abstract}
RESUMO: A yoz de um editor popular remete a um trabalho em curso. Estăo sendo estudados e inventariados livros e editoras populares. O tópico memória editorial brasileira é uma proposta, e nele, o projeto Editando o Editor, desenvolvido na ECA-USP, em publicaçấo conjunta com EDUSP. O foco vai aqui para o universo que defini como "A indtistria do livro num país oral". Assim, apresenta-se o depoimento de Savério Fittipaldi (sobrinho do editor homônimo) numa visita feita a ele por mim e pelos alunos das disciplinas Livros Populares, que confirma a vitalidade e deixa entrever os rumos da ediģî́o de livros destinados a públicos populares, no Brasil.
\end{abstract}

PALAVRAS-CHAVE: Livros e Ediçōes populares, memória editorial, editora Luzeiro e Fittipaldi, Literatura Oral, Repertório Oral/Impresso.

Ao atuar numa Escola de Comunicações e, ter de oferecer cursos na área de Editoração, procedi a uma revisão crítica que me levou a pensar que ao invés de propor panoramas, o melhor seria, num território tăo novo, ir gerando os próprios materiais.

A historia do livro, as práticas de leitura, os conceitos de livro, texto, autor, edição, estiveram em causa num projeto mais amplo que criei: Memória Editorial Brasileira, em que se insere o projeto Editando o Editor COM-ARTE - Edusp.

A partir de um dado momento, e contando com elementos de minha própria pesquisa pessoal que trata de livros e edições populares, fui pensando numa ampliaçáo do projeto fazendo voltar-se para um outro tipo de circuito do livro e da leitura, na medida em que foi-se levando em conta o "livro popular e de massa". Está em curso o mesmo tipo de trabalho que fizemos com os outros editores, agora tendo como protagonista Arlindo Pinto de Souza, da Editora Luzeiro (texto no prelo), responsável pela edição da nossa literatura de Cordel, e atuando intensamente junto aos públicos populares, com os mais diversos produtos editoriais.

- Professora Associada da Escola de Comunicações e Artes - ECAVUSP 
FERREIRA, Jerusa Pires. A voz de um editor popular.

\section{Livros e Editoras Populares}

Temos o hábito de pensar a literatura popular como a tradicional, proveniente de uma memória "despótica", regida, por antigas matrizes de expressão. Não podemos esquecer porém que a tradição popular tem o suporte do impresso, dos meios que foram reproduzindo e sedimentando alguns caminhos do imaginário. Ao falar em livro popular num país de tradiçáo oral como o nosso, temos de pensar nos folhetos daquela literatura que ficou sendo conhecida como de Cordel. Ela compreende desde o folheto mais artesanal, produzido por diversas gráficas nordestinas até aquele industrializado em São Paulo pela Editora Luzeiro. Vai-se seguindo uma espécie de circuito de transição, que se apoia, tanto no processo industrial em larga escala, quanto no apelo aos repertórios mais tradicionais, e à veiculação dos repertórios consagrados. Algumas editoras nos vão oferecendo os passos dessa transição. Assim considerei, neste item da memória editorial, ser indispensável um mapeamento urgente das editoras que produziram e produzem livros populares, no eixo-industrial Rio-São Paulo, achando que outros levantamentos e fixação de dados deverăo ser feitos, sempre que possível.

Acompanha-se, através da observação destas editoras populares, o trânsito entre o universo da cultura popular tradicional e o da cultura de massas. Por enquanto, nos ocupamos basicamente de levantar os projetos e perfil editorial de editoras populares. No caso a editora João do Rio fundada em 1921 por Savério Fittipaldi, um imigrante italiano, cujo nome parte de uma homenagem que ele resolveu fazer ao cronista carioca Paulo Barreto, personagem muito famosa no período - começo do século no Brasil - autor de as Religiôes do Rio.

Está em preparação um estudo detalhado sobre o editor e a editora que se dirigiu, com grande sucesso, aos públicos populares urbanos da mais diversa proveniência, entre os anos de 1921 a 1937.

Savério Fittipaldi aproveitou para divulgar alguns projetos pioneiros: fazer circular os clássicos em adaptações facilitadas, a informação cientificizante ao alcance de todos, os fascículos de História Universal, os livros policiais e de crimes, e um ciclo nordestino com histórias sucessivas de Lampeão e do Cangaço.

Quanto aos livretos políticos, ao mesmo tempo que se encontram biografias de Mussolini e de Oliveira Salazar conforme suas inclinações, edita-se o anarquista Pedro Kropótkin, e acha-se um curioso livrinho, a História de Augusto C'esar Sandino e a Invasão da Nicaragua pelos Estados Unidos publicado em 1928, o que nos deixa perplexos! Pelo trabalho que se está fazendo com o que sobrou da Editora e da atividade editorial, vê-se o 
quanto se pode ainda recuperar desta memória e o quanto está irremediavelmente perdido.

O trabalho se desenvolve a partir de um caixote de "sobrados" que foram guardados em poder de Mario Fittipaldi, seu filho, e dos esclarecimentos e informações que me passou e que foram anotadas. Está em curso, há bastante tempo, um estudo detalhado, que procura levar em conta o projeto editorial, os textos produzidos, a circulação e as tiragens, os autores e sua polivalência, os ilustradores, o carisma do editor, a partir dos textos escritos em forma de prefácio ou de introdução. São os próprios livretos com seus anúncios em quarta capa - o rol de obras que ali se anunciam - que nos dão a dimensão e 0 alcance deste projeto editorial junto aos públicos populares. Nas disciplinas que criei na ECA-USP e que trata de livros e edições populares, temos agora como tarefa o levantamento e estudo da editora Saverio Fittipaldi, uma outra editora, fundada pelo sobrinho do antigo editor, e que nestas últimas décadas responde por uma razoável produção de livros populares em São Paulo. Confirma-se aqui a tradição familiar e uma espécie de dinastia de profissionais do livro, ao modo daquelas que na França apontaram Robert Mandrou e Geneviève Bollème em seus estudos pioneiros.

\section{SAVÉRIO FITTIPALDI E O LIVRO POPULAR: UMA HISTÓRIA EDITORIAL}

Eu estava rememorando o meu ingresso no ramo editorial. Meu tio, Savério Fittipaldi, meu xará, já era editor, há muitos anos, no Rio de Janeiro, com a célebre Editora e Livraria Joăo do Rio. Meu pai chamava-se Vicenzo. Tornou-se comendador ao receber do governo italiano uma comenda por bravura de guerra, durante a Primeira Guerra Mundial, da qual participou do começo ao fim, fazendo sempre combates de $1 \mathrm{a}$. linha. Ele era dois anos mais jovem que meu tio, que também fez a guerra. Os dois faleceram em um intervalo de um mês, parece até que foi combinado, os dois estavam sempre juntos.

Quem começou com a editoração no Brasil foi meu tio, até que meu pai veio para São Paulo e tornou-se editor; e eu sempre acompanhando. Foi um acontecimento natural, de pai para filho, sempre uma paixão tremenda pelo ramo, apesar de terem surgido diversas oportunidades para outras atividades. Sou advogado, advogado dentro da editora e atendo meus amigos, mas essa não é a minha paixão. 
Nasci no mesmo lugar que meu tio San Severino Lucano, Potenza, província de Basilicata, Itália. Isso é na região de Basilicata na Calábria. Então, aos três anos de idade vim para o Brasil e fui morar dentro de um depósito: a casa de meu pai era um depósito da livraria João do Rio aqui em São Paulo, era uma casa muito grande onde o dormitório era exatamente o lugar em que se estocavam todas as publicações.

Meu pai era representante do meџ tio; recebia as mercadorias, as edições lá do Rio de Janeiro e fazia a distribuição aqui.

Houve, então, uma crise, lá no Rio de Janeiro, no país todo. Foi quando meu tio fechou a editóra lá e veio para São Paulo; e nós continuamos aqui, crescendo.

Quando alcancei a idade de dezenove anos, comecei a minha primeira editora, isso como empresa, porque eu trabalhava desde criança; aos onze anos de idade meu pai já me pôs no caminho. Eu via aqueles livros, as coisas bonitas que eram feitas, não só pelo meu tio, mas também o que encontrava pelas livrarias, e fiquei apaixonado por isso. Comecei a editora depois de ter me formado perito contador, o que possibilitou fazer os primeiros originais, de minha autoria, mesmo porque eu estava começando do nada e não tinha condições de pagar autores.

Um dos primeiros livros de porte foi o Mestre dos Mestres, um livro comercial que abordava toda a prática dos escritórios: modelos de cartas, procurações, assuntos de português e contabilidade, que era a minha especialidade. Tenho ainda diversos originais, cerca de uns quinze livros, dos mais diferentes, de quando eu comecei a trabalhar nesse ramo. Alguns deles foram publicados sob pseudônimos, como um livro médico que contou com a ajuda de um doutor de verdade, na parte prática das receitas e medicamentos. Naquele tempo os médicos costumavam aviar as receitas, não se compravam os remédios prontos.

A primeira editora criada chamava-se Fittipaldi Savério, porque eu ainda era italiano naquela ocasião. Depois admiti meus irmãos como sócios e o nome mudou para Fittipaldi Savério e Irmãos Ltda, e foi assim por muitos anos, até 1973, quando encerrei essa fase.

Logo em seguida comecei a Saber, que hoje é dirigida por meu filho, Hélio Fittipaldi. Na Saber ele continuou a publicação de uma revista de eletrônica que nascera na antiga editora (onde comecei a arregimentar os colaboradores para produzir a revista toda).

Hélio prosseguiu com a Saber e em 1981 eu registrei a outra editora, a Savério Fittipaldi (por essa ocasião eu me tornara brasileiro). Meu filho, Vicente Fittipaldi entrou na sociedade e, em 1984 a firma individual passou a ser Editora Fittipaldi Ltda. 
Desde pequenos eu trazia meus filhos para a editora a título de lazer. Eles foram se habituando e gostando. Meu pai já era editor nato, como eu também. Está no sangue.

Minhas primeiras publicações foram livros populares. O primeiro foi Cartas de Amor, o segundo foi o Livro dos Sonhos e o terceiro, Mestre dos Mestres. O Mestre dos Mestres é um livro de trezentas e poucas páginas do qual eu chegava a fazer tiragens de 25.000 exemplares na Revista dos Tribunais. Quando era feita a entrega, vinham dois caminhões daqueles grandes carregados e lotavam meu depósito na rua Almirante Barroso, no Brás (perto de "seu" Arlindo da Editora Luzeiro).

Logo em seguida fiz o Mensageiro do Amor, que também eram cartas de amor; Gravidez e Parto, um livro médico, e $O$ Chofer. Depois comecei com publicações populares de outros autores.

Escrever não era só interessante, era sobrevivência. Eu fazia tudo: escrevia, levava para a gráfica, fazia revisão, recebia a mercadoria da gráfica e saía para vender a edição. O negócio era sacrificado mesmo; durante o dia eu vendia, à noite, escrevia.

Os temas escolhidos eram baseados em minha prática das vendas, ela leva a saber justamente o que o público quer. Antigamente, nós tínhamos, condições muito melhores para vender do que agora; parece até que diminuiu o número de leitores. A televisão e os outros meios foram substituindo o hábito de ler, tudo isso, além do aumento da crise.

Nos primeiros cinco anos da editora, eu vivia às custas dos meus livros. No ano de 1968, comecei a publicar histórias em quadrinhos; comprava os direitos da editora, traduzia e adaptava os desenhos estrangeiros, vindos dos EUA: Fantasma, Mandrake, Recruta Zero, Príncipe Valente e Popeye, entre quarenta personagens diferentes. Isso aconteceu de 1968 a 1975 , quando terminou o contrato com o King Features Syndicate, mas eu nunca gostei de fazer coisas estrangeiras. Mesmo dando oportunidades de trabalho a muitos desenhistas brasileiros, eu sempre primei pela produção nacional.

Depois comecei a contratar autores nacionais para escreverem obras populares, que publico continuamente: livros de sonhos, cartas de amor, piadas. As piadas com as quais comecei foram de Bocage - o único original que me veio à mão na época - e hoje fazemos uma infinidade de piadas mensalmente: de português, de sogra, de japonês, num total de dez tipos diferentes. Nesses livros, o autor é o próprio desenhista, que cria ou se baseia em outras piadas ou histórias para escrever. Além dessas séries, fazemos uma publicação mensal que chamamos de Simpatias. Publicamos um horóscopo mensal, chamado Diário, e um anuário, também na versão de horóscopo chinês. O horóscopo mensal fol desdobrado em um semanal, com previsões 
FERREIRA, Jerusa Pires. A voz de um editor popular.

para cada semana, dia-a-dia. Pelo retorno que temos em termos de vendas, é fácil perceber que as pessoas andam muito inseguras e compram tudo o que está relacionado às superstições.

A editora lançou também uma publicação sobre armas e munições chamada Hunter, que foi uma boa surpresa pelos elogios que recebeu, inclusive de profissionais desse meio.

Informamos sobre a fabricação das armas, a munição usada, advertimos o público em geral sobre os cuidados que se deve ter ao fazer-se uso delas, etc. A tiragem do primeiro número foi de cinqüenta mil exemplares, mas deveria ter sido bem maior para atender a demanda. No número dois esperamos ver a quantidade pedida pelo distribuidor, pois é ele quem está mais próximo do público.

No começo da minha trajetória editorial eu fazia tudo, até pesquisa, baseada na minha experiência, no meu dia-a-dia. Mas de uns anos para cá esse procedimento mudou muito, existindo uma equipe do distribuidor que nos auxilia fazendo a pesquisa, que já não pode ser na base do "vamos lançar e ver se vende", como antigamente.

Naquele tempo eu editava a história do Carlos Magno, uma leitura romanesca, que saiu em três edições e depois perdeu a razão de ser. Digo isso porque o rádio e a televisão se encarregaram de destruir o hábito da leitura. Hoje, as pessoas preferem seguir uma novela a ler um livrinho desses que era o passatempo da época.

Editei Os Três Mosqueteiros, $O$ C'onde de Monte Cristo, Memórias de um Médico, Vinte Anos Depois, O Máscara de ferro, todos de Alexandre Dumas. Eram quarenta volumes vendidos em coleções completas encadernadas ou como exemplares avulsos, um por mês. Dos autores nacionais fiz a coleção completa de José de Alencar. Fui também o único editor a publicar livros em miniatura, com três centímetros de altura.

Um grande sucesso foram as edições das músicas de Roberto Carlos, que já em seus primeiros volumes me renderam um processo por direitos autorais que é a única medalha que trago como editor. Como já é notório, diversos autores compõem as letras de suas músicas, sendo creditada a ele a autoria das mesmas na contracapa de seus discos. Entrando num acordo com os verdadeiros autores (entre eles, Fred Jorge, autor da série Cartas de Amor), iniciei a publicação das letras. Porém, por descuido, só fui saber tarde demais que algumas das letras foram compostas pelo próprio cantor, o que permitiu que eu fosse processado e acabasse por ter que lhe pagar os direitos. Aprendi muito com essa situação e hoje o trabalho continua através de meu filho, só que ele recebe as letras diretamente dos autores. 
R. História, São Paulo, n. 125-126, p. 105-115, ago-dez/91 a jan-jul/92.

Publicamos também muitos livros que classificamos como esotéricos: o Catecismo de Umbanda, Preces Espíritas, a Cruz de Caravaca, todos que proponham aperfeiçoamento da pessoa. No caso do Livro de São Cipriano, do qual já fiz várias edições, eu poderia dizer que atingi uma maturidade espiritual que não me permite mais publicá-lo, apesar de ser produzido por muitas outras editoras. Esse livro é um incômodo porque não tem a finalidade de ensinar algo bom, ele desvirtua a mente humana. Tenho também um original chamado a Bruxa de Évora que eu não tenho intenção de publicar pelos mesmos motivos.

Dentre as publicações populares editamos também livros de lutas, como caratê, judô e defesa pessoal que de acordo com a reação do público ao lançamento vão sendo renovados, desdobrados ou cancelados definitivamente. Aproveitamos a preferência do público e vamos publicando. Foi a mesma coisa que fizemos com a revista de eletrônica.

\section{Público}

O perfil do nosso leitor corresponde a um público de baixa renda, com nível de instrução bastante elementar, baseado naquele saber antigo. Muitos deles compravam os livros e mal sabiam ler, eram atraídos pela capa.

Naquela época, a leitura era, muitas vezes, comunitária; uma pessoa mais instruída lia para os outros. Aqueles que compravam minhas Cartas de Amor usavam-nas como modelos para escrever para outras pessoas que não sabiam ler.

Hoje isso mudou muito. Eu continuo a publicar as cartas de amor, já de um modo aperfeiçoado, mas o público mudou. Os leitores de cartas de amor são pessoas solitárias, que têm um desajuste familiar, que compram os livros com a finalidade de pensar que aquelas cartas estão sendo enviadas para elas, numa tentativa de fuga da solidão.

Eu estive fazendo um levantamento e cheguei à conclusão de que as pessoas com falta de afeto são exatamente os compradores.

Nós vendíamos sabendo que as pessoas compravam para tirar o modelo, copiando aquilo como se fossem elas que estivessem formulando as cartas e isso já mudou. Apesar de não termos dados, sabemos também que a faixa de instrução do nosso público regrediu um pouco. Vejo muitos porteiros de prédios, dentro daquelas caixas de vidro, lendo essas publicações.

Estou fazendo uma nova edição de Cartas de amor a cada mês, com uma tiragem em torno de 30.000 exemplares, que não chega a se esgotar. Por isso temos grandes armazéns para ir acolhendo os encalhes. 
FERREIRA, Jerusa Pires. A voz de um editor popular.

\section{Vendas / Produção / Quantidade}

Distribuição através de livreiros para nós não existe. Nossa venda é feita para jornaleiros. Nesse particular, posso me orgulhar de termos sido, meu pai e depois eu, os pioneiros na introdução da venda dos livros em bancas de revistas.

Os jornaleiros não vendiam livros, em primeiro lugar, porque era proibido pela prefeitura do Rio de Janeiro. Não era permitida a venda de outras publicações que não fossem jornais e revistas. Autorizaram a venda de bilhetes de loteria, chaveiros e toda variedade de objetos, exceto o livro. Já em São Paulo tivemos que convencer um a um os jornaleiros, porque em sua mentalidade eles achavam que o ponto de venda (a banca), não comportava um artigo de maior custo, maior porte. Preferiam vender jornais e revistas, por somente.

Quanto ao número de livros editados, acho que estamos em torno de uns dois mil. Nós lançamos praticamente uma publicação por dia entre livros e revistas, o que dá um total de vinte e oito publicações por mês, sempre com grande diversidade

Nosso movimento gira em torno de um milhão e duzentos mil exemplares por mês, enquanto dizem no mercado que três mil exemplares representam uma boa média. Acho graça nesse tipo de conversa que às vezes aparece na televisão e nos jornais. Se eu tivesse feito essa média de tiragem naqueles mesmos tempos em que eu fazia duas tiragens de vinte e cinco mil exemplares de Mestre dos Mestres por ano, eu não teria chegado até os dias de hoje.

Ninguém pode sobreviver assim, porque fazendo uma tiragem pequena o preço, obrigatoriamente, terá que ser revisto, pois se você vende mais caro tem menos leitores. A minha filosofia sempre foi a de fazer tiragens maiores para vender mais livros por um preço menor. Sempre fiz assim, nunca houve uma tiragem inferior a vinte mil exemplares, sendo que a maior foi de cinqüenta mil. Agora que estamos numa recessão muito triste, fazemos, em média, uma tiragem de vinte mil exemplares.

Existem alguns títulos que sustentam a editora. São os livros populares, as cartas de amor, os livros de sonhos, a eletrônica, o figurino, as piadas e os eróticos.

No campo dos eróticos fazemos oito publicações por mês, numa média de dois por semana. São romances e contos rápidos, descrevendo o ato de amor em detalhes, mas sem fazer uso de figuras pornográficas, que nunca fiz e não gosto de fazer. Como eles não podem ser exibidos nas bancas por serem proibidos para menores, os livros vêm envoltos em plástico, igualmente 
acontecendo com alguns livros de piadas, de acordo com as gravuras das capas. Infelizmente, sem esse tipo de publicação a editora acaba não resistindo. É a sustentação finaceira que advém delas, contudo, que me permite sonhar com a publicaçáo dos clássicos, que gostaria muito de fazer, por uma vaidade. A Editora Abril também publicou clássicos por vaidade, porque suas tiragens estão bem abaixo da média, o que acarreta um preço mais alto, que nem todos podem pagar. Eu tenho uma posição mais idealista: quando faço uma publicação é para dar tudo o que é bom para o leitor, sempre procurando um preço menor. Quando faço uma edição, é a definitiva. Nunca fiz duas edições de um mesmo livro, uma mais cuidada e outra mais simples para atingir públicos diferentes. Nunca compactuei com a idéia de publicar certos originais que apenas uma elite teria condiçôes de comprar, para ganhar ali a compensação das ediçóes de preço baixo.

\section{Os Autores e Ilustradores}

Hoje eu tenho muitos autores contratados, produzindo para a editora, que escrevem usando pseudônimos. Alguns deles, os que dominam determinada matéria, são permanentes, outros são free-lancers, escrevendo um ou outro original e só.

Os autores contratados por tarefa são: Newton Braga, que responde pelas revistas de eletrônica da Saber e que é publicado aqui (na Editora Fittipaldi Ltda.) com o nome de J. Martins; o Rubens Luchetti, que produz todas as publicações esotéricas, além de ter feito Drácula e Sherlock Holmes; Edson Gomes, autor daquelas obras de direito - o famoso doutor Guastini. Todos eles trabalham há anos para mim.

Os autores fixos são quatro ou cinco diferentes que fazem as piadas e escrevem sempre usando pseudônimos, sem nunca aparecer. Todos eles não só desenham como também elaboram o argumento.

Já os ilustradores, fazem a apenas as capas e, às vezes, a matéria interna. Eduardo Castro Pereira era um ótimo ilustrador que já faleceu. Ele trabalhou muitos anos comigo. Produzimos uma história em quadrinhos com argumento e personagens meus e desenhos dele. Depois, quando suspendi a publicação, Eduardo foi para a editora Ática, mas acabou voltando para nós e fazendo todas as capas das publicações de simpatias pois adorava esse assunto.

Meu tio Savério trabalhava com um corpo de ilustradores fantásticos. o Casa Nova era uma maravilha; a Antonieta era uma beleza. Havia também - Nico Rosso e Jayme Cortez que fez a maioria das obras, as capas de 
FERREIRA, Jerusa Pires. A voz de um editor popular.

Sherlock Holmes e a produção do horóscopo. Esse todos são fixos, fazem ilustrações, desenhos e textos e estão conosco há anos.

\section{Projetos Editoriais}

Atualmente, tenho uma programação para publicar os clássicos: $A$ Divina Comédia, de Dante Alighieri; a obra de Miguel de Cervantes, Dom Quixote, usando as mesmas ilustrações originais de Gustavo Doré; Os Lusíadas, de Camões e $O$ Paraíso Perdido, de Milton. Essas eram as quatro primeiras obras que eu já tinha programado. Publicar clássicos é a única coisa que falta na minha trajetória editorial.

Estamos ainda planejando uma Bíblia. Meu filho e eu fomos à Cúria Metropolitana ver o original, pois ainda não tínhamos definido qual o tipo de publicação que faríamos, se no mesmo formato ou em tamanho grande. A idéia agora é fazer uma Bíblia em tamanho comum, em um único volume.

Fora essa publicações, já fiz de tudo em termos de editoração, inclusive jornal. Enquanto eu sofria aqui com a editora, criei uma empresa gráfica e jornalística chamada Observador Literário, com uma publicação dedicada a divulgação da produção literária de todas as editoras. Apresentávamos uma fotografia da capa e depois uma explicação do que tratava cada livro, quantas páginas tinha, enfim, fornecer um panorama editorial por meio de um catálogo. Esse trabalho começou em 1964 e durou apenas uns cinco anos por causa do fracasso financeiro que representou.

\section{O papel do editor}

Quando entrei na Faculdade de Direito na década de setenta, meus professores, os diretores e também meus amigos, não me tratavam como aluno e sim como editor. Durante o curso, publiquei obras de todos os professores que tinham algum trabalho para editar. Fiz a coleção de Direito Civil do professor Guastini - nove volumes abrangendo todas as áreas de direito -, Medicina Legal do professor José Antônio de Melo, diretor do IML de São Paulo, que foi reeditado várias vezes e na última edição trouxe uma das últimas conquistas da ciência médica: investigação de paternidade. Fiz também Direito Constitucional do Eder Americano, a Constituição e um Código de Processo Civil; tudo isso porque eu estava na área e queria acompanhar todo o desenvolvimento da matéria.

Uma outra área que desperta meu interesse é a medicina, que eu gostaria de ter estudado. No último ano de Direito eu cursei medicina legal 
que, apesar de superficial, era muito interessante. Cheguei, inclusive, a acompanhar o professor Melo no Instituto Médico Legal, em várias autópsias, como se fosse um médico. $\mathrm{O}$ que fiz nesse campo foi também publicar vários livros. O primeiro deles foi Gravidez e Parto, na ocasiăo em que nasceu meu primeiro filho - talvez eu tenha sido influenciado pelo ambiente.

Fico imaginando se não tivesse eu me dedicado à editoraçăo, tivesse outra intençáo que não fosse a de ganhar dinheiro apenas para a sobrevivência, se tivesse seguido outra atividade, não teria eu obtido um resultado financeiro melhor. Teriam sido, porém, coisas contra a minha vontade. É verdade, que dediquei-me por algum tempo a atividades como a construção civil, compra e venda, mas nada disso teve continuidade.

O editor é um mestre por excelência porque procura dar tudo de si para seu semelhante, sempre com a intenção de melhorar, fazer progredir, aperfeiçoar. Essa é sua luta constante e essa é minha paixão. Nasci para ser editor. Sempre fiz tudo com o prazer enorme de oferecer ao próximo a oportunidade do saber, de adquirir conhecimentos.

\section{Savério Fittipaldi}

Como parte das atividades do curso Edição de Livros Populares II, oferecido no $2^{\circ}$ Semestre de 1991, os alunos Elissa Albert El Khoury e Marcelo Fernandez Cuzziol, com o acompanhamento e supervisão da Prof Jerusa Pires Ferreira, entrevistaram o editor Savério Fittipaldi, diretor-presidente da Editora Fittipaldi, no mês de outubro daquele ano. A entrevista ocorreu na própria editora, situada à rua Major Ângelo Zanchi, bairro da Penha, São Paulo.

Em outubro de 1992, dentro do mesmo curso e ainda sob a orientaçăo da prof Jerusa, trabalharam na preparação do texto da entrevista os alunos Aline Sanchez Leme, Eda Gomes Lambert e Alberto Takeshi Mayama.

ABSTRAC.T - The voice of a popular editor points to a work in progress. Popular books and publishers are currently being studied. The topic "Brazilian Publishing Memory" is a definite proposal and contains the project "Editing the editor" in line, at the Communication and Arts School of the University of São Paulo and EDUSP.

The focus of this project is directed to the universe 1 defined as the book industry in an oral (pre-literate) country. Therefore, the interview presented in this article is of Saverio Fittipaldi (nephew of the homonimous publisher) when the students of the disciplines Popular Books and I visited his pu- 
FERREIRA, Jerusa Pires. A voz de um editor popular.

blishing house. It confirms vitality and makes possible to foresee some trends of publishing and editing books for popular and illeterate public in Brazil.

KEY-WORDS: Popular Books, popular publishing houses, memory of editions, Luzeiro Fittipaldi Publishing House, Oral Literature Literacy. 